NBER WORKING PAPER SERIES

\title{
THE EFFECT OF IMPROVEMENTS IN HEALTH AND LONGEVITY ON OPTIMAL RETIREMENT AND SAVING
}

\author{
David E. Bloom \\ David Canning \\ Michael Moore \\ Working Paper 10919 \\ http://www.nber.org/papers/w10919
NATIONAL BUREAU OF ECONOMIC RESEARCH
1050 Massachusetts Avenue
Cambridge, MA 02138
November 2004

The views expressed herein are those of the authors and do not necessarily reflect the views of the National Bureau of Economic Research.

(C) 2004 by David E. Bloom, David Canning, and Michael Moore. All rights reserved. Short sections of text, not to exceed two paragraphs, may be quoted without explicit permission provided that full credit, including (C) notice, is given to the source. 
The Effect of Improvements in Health and Longevity on Optimal Retirement and Saving David E. Bloom, David Canning, and Michael Moore

NBER Working Paper No. 10919

November 2004

JEL No. J26, D91

\begin{abstract}
$\underline{\text { ABSTRACT }}$
We develop a life-cycle model of optimal retirement and savings behavior under complete markets where retirement is caused by worsening health in old age. Our model explains the long-run decline in the age of retirement as an income level effect. We show that improvements in health and longevity tend to increase the desired retirement age, though less than proportionately, while, contrary to conventional views, reducing savings rates. The retirement age is not simply proportional to healthy life span because compound interest creates a wealth effect when lifespan increases, leading to more leisure (early retirement) and higher consumption (lower savings).

David E. Bloom

Harvard University

Department of Population and International Health

Building I, Room 1110B

677 Huntington Ave.

Boston, MA 02115

and NBER

dbloom@hsph.harvard.edu

David Canning

Harvard School of Public Health

Harvard University

dcanning@hsph.harvard.edu

Michael Moore

Queen's University

Belfast

m.moore@qub.ac.uk
\end{abstract}


Among the most remarkable changes in human welfare that took place in the 20th century was the improvement in health and the related rise in life expectancy. For the world as a whole, life expectancy at birth rose from around 30 years in 1900 to 65 years by 2000 (and is projected to rise to 81 by the end of this century; Lee 2003). These improvements have not only resulted in a large direct gain in welfare (Nordhaus 2003), but have presumably also had a profound influence on economic life-cycle behavior by changing people's time horizons (Hamermesh 1985).

We focus on two fundamental, interrelated issues in life-cycle behavior, namely, retirement and consumption patterns. One of the central reasons for saving is to provide income for retirement. This life-cycle theory of saving and retirement is not a complete model. For example, people also engage in precautionary savings to guard against income shocks, and they may also save to provide bequests. In addition, in many developing countries the elderly are supported to a large extent by intra-family transfers, while many industrial countries have widespread social security systems that support the elderly. These transfer systems clearly affect incentives to save and to retire.

Notwithstanding its incompleteness, the life-cycle model can provide valuable insights into behavior. In this paper we develop a theoretical model of retirement and consumption based on individual optimization over the life cycle with complete and perfect capital markets. As well as offering a positive theory for observed behavior, such an approach offers an insight into the welfare effects of proposed changes to social security systems. Many social security systems are based on pay-as-you-go financing, which involves transfers from current workers to current retirees. Increased life expectancies, together with low birth rates, promote aging populations, which can impose great financial stress on such systems. As a result, increases in contribution rates for workers, reductions in benefits to retirees, or increases in the age of retirement may be 
necessary to ensure financial solvency. Insofar as social security systems try to promote the optimal retirement and consumption outcomes rational agents would make with perfect markets, in an effort to overcome widespread lack of foresight about the need to save for retirement, time inconsistency in preferences (Feldstein 1985; Laibson 1998; Laibson and others 1998), or capital market imperfections (Hubbard and Judd 1987), the results of our model can serve as benchmarks in the design of public pension systems. It is important to note, however, that our model does not take into account possible negative externalities on others that occur if people suffer an impoverished old age (Kotlikoff, Spivak and Summers (1982)), or potential welfare gains from intergenerational transfers as, for example, in Samuelson (1958). These effects might make the optimal social security system have higher levels of forced saving, or a redistributional element.

Several papers have tackled the issue of how changes in longevity affect retirement and consumption decisions. The two most similar to our approach are Chang (1991) and KalemliOzcan and Weil (2002). In these papers agents maximize lifetime utility over consumption and leisure, and the optimal retirement age and optimal consumption profile over time are jointly determined. Both papers emphasize the possibility that while longer lifetimes typically increase the optimal retirement age, under some circumstances the desired age of retirement may decline as life expectancy increases. A key mechanism for this to occur is an imperfect annuity market, so that in an environment with a high death rate the return to saving is uncertain, because the wealth stock accumulated is likely to be wasted when the agent dies. When life expectancy increases and mortality falls this "uncertainty effect" declines, and the prospect of saving for retirement becomes more appealing. In addition, these papers assume that increases in life 
expectancy have no effect on health and the disutility of working at each age, so that any incentive to retire early because of poor health remains unchanged.

We assume complete capital markets, in particular, the existence of (perfect) annuity markets. However, the major innovation in this paper is to model health during the agent's lifetime and its effect on the decision to retire. Rather than impose a fixed disutility of working, we assume that the disutility of work depends on a worker's health status. A great deal of evidence indicates that retirement is linked to poor health (see, for example, Sickles and Taubman 1986), although there are serious concerns about the accuracy of health measurements (Bound 1991).

An important feature of our model is our assumption that rising life expectancy goes hand-in-hand with improved health status at each age (that is, we examine a life span that is both longer and healthier). Increases in life expectancy in the United States over the last two centuries have indeed been associated with reductions in the age-specific incidence of disease, disability, and morbidity (Costa 1998a; Fogel 1994, 1997). Mathers and others (2001) show that healthadjusted life expectancy (each life year weighted by a measure of health status) rises approximately one for one with life expectancy across countries. This motivates us to use a model in which health status rises with life expectancy, so that the age of onset of illnesses that increase the disutility of labor rises proportionately with life expectancy.

In our analysis we find that the behavioral effect of improved health and longevity on optimal retirement age is ambiguous, but we can determine the direction of the effect under "reasonable" assumptions. For example, we assume that the optimal retirement age is less than life expectancy, which seems plausible in industrial countries, but may be a less appealing 
assumption in developing countries. In addition, we assume that interest rates are not "too high" and are comparable to the rate of time preference.

Using this framework, we show that the effect of increases in health and life expectancy is to increase the optimal retirement age, although it rises less than proportionately with longevity, so that the fraction of the life span spent in retirement rises. At the same time, consumption at each age rises and savings rates fall.

This result contrasts with the argument that an increase in longevity and an increased need for retirement income may have been a driving force for increases in savings, particularly the boom in household savings in East Asia over the last fifty years (see Bloom, Canning, and Graham (2003), Lee, Mason, and Miller (2000), and Tsai, Chu, and Chung (2000)). Deaton and Paxson (2000) point out that this savings effect seems reasonable when the retirement age is fixed but argue that in a flexible economy, without mandatory retirement, the main effect of a rise in longevity will be on the span of the working life, with no obvious prediction for the rate of saving. Kotlikoff (1989) similarly argues that the main effect of a rise in longevity will be on the length of the working life and analyses the effect on the economy when working life increases proportionately, and when it rises an equal number of years (that is, more than proportionately). We formalize the analysis of savings behavior in response to increased longevity when the retirement age is endogenous and have the prediction of a less than proportional rise in the retirement age and a decrease in the savings rate.

This new result arises primarily because we allow for an improvement in health when life expectancy rises, which encourages a longer working life because of a lower disutility of labor. At first sight, it is tempting to imagine a proportionality result where working life is proportional to life expectancy, and consumption and the saving rate remain unchanged. However, this 
conjecture ignores the fact that the agent's longer working life permits greater exploitation of the accumulation of compound interest on savings. The increased opportunity to exploit the benefits of compound interest generates higher potential wealth at retirement than before; this "wealth effect" of a longer life span allows for both an increase in leisure, in the form of the proportion of the life span spent in retirement, along with somewhat higher consumption (and hence lower saving) at each age, assuming that both consumption and leisure are normal goods.

Our results lead us to argue that the long-term decline in the age of retirement in industrial countries over the last 150 years (Costa 1998b) has not been due to improvements in health and life expectancy; instead, we point to the potentially large effect of the level of wages as a driving force behind earlier retirement, which coincides with Costa's (1998a) analysis. Our model also suggests that the emergence of jobs with lower disutility of labor, lower interest rates and higher wage growth lead to a delay in retirement, and may help explain the recent rise in the average age at retirement in the United States (though Friedberg and Webb 2003 emphasize institutional changes as the explanation).

In our model we treat the interest rate, disutility of labor, rate of time preference and rate of wage growth, as exogenous and fixed in our of analysis of the effect of a rise in life expectancy. In a general equilibrium model, aging populations may generate large stocks of capital as they save for retirement and this can drive down the return to capital, lowering the long run interest rate. Our model predicts that this will lead to longer working lives, and lower savings rates among workers. However, Miles (1999) and Poterba (2004) suggest that the returns to capital decline very slowly with expansions in the capital stock and population aging in developed countries will lead to only a small decline in the rate of return. Cutler, Poterba, Sheiner, and Summers (1990) suggest that population aging and lower rates of labor force 
growth may increase the rate of technical progress, which may lead to a higher rate of wage growth, though again the size of the potential effect seems modest.

We examine retirement and savings in the context of complete markets. Of course, our results would change dramatically in the presence of institutions or market imperfections that limit choice or change the incentives for retirement and saving behavior. As already noted, a lack of complete financial markets, particularly annuity markets, increases the incentive to save as mortality rates fall. More directly, mandatory retirement in some occupations may prevent individuals from responding optimally to longer life spans and force higher savings rates. Even in the absence of mandatory retirement, substantial evidence indicates that retirement in industrial countries, particularly in Western Europe, clusters around specific ages that depend on retirement incentives inherent in the national social security system (Gruber and Wise 1998).

Our model suggests that social security systems that have a mandatory age of retirement, or that impose disincentives to work past a normal retirement age, may impose a welfare loss, and that this loss is likely to become larger as health and longevity improve, and the optimal retirement age rises. On the other hand, rising levels of income may encourage early retirement making such constraints on the length of working life less binding. ${ }^{4}$

We present our model in section I and show how the dynamic programming problem facing agents generates a set of equations (derived from the first-order conditions) that determine the optimal retirement age and consumption profile. In section II we find solutions for the optimal retirement age and consumption profile and investigate how these change with changes in the parameters of the model. Finding the optimal retirement age and consumption rule in the

\footnotetext{
${ }^{4}$ It is not necessary to set a retirement age for social security. An alternative system is to fix contribution levels and allow a free choice of retirement age with actuarially fair social security benefits, as is done in the United States and is being implemented in Sweden. Our model suggests that this type of system will lead agents to endogenously choose a higher retirement age as their health improves and their life expectancy rises.
} 
simple case where the interest rate, rate of time preference, and rate of wage growth are all zero is fairly straightforward. However, for the more general case a full solution is not available, and we use the implicit function theorem to derive an approximate solution that holds for the case where the rates of interest, time preference, and wage growth are reasonably small. Section III summarizes and discusses our main results and suggests avenues for further research.

\section{The Model}

We examine the optimizing problem of agents deciding their lifetime labor supply and consumption and take the real wage rate, $\omega$, and interest rate, $r$, to be exogenous. We assume that the interest rate is fixed over time, but that real wages grow at the rate $\sigma$, reflecting long-run economic growth.

For simplicity, we assume an exogenous, constant death rate; a more realistic mortality schedule would allow for rising death rates as people age. We ignore the possibility of using consumption and health services to extend longevity (Ehrlich and Chuma 1990), or of a reverse link from labor supply to health status and life expectancy. We also assume that working life starts at the very beginning of the life cycle, with no period of schooling. A more complete model would also allow for the endogenous choice of schooling, along the lines of KalemliOzcan, Ryder, and Weil (2000). In addition, we assume that agents do not make bequests, which rules out a potential mechanism through which changes in life expectancy among current and future generations can affect labor supply and savings behavior (Skinner 1985).

Given the constant death rate, $\lambda$, the probability of being alive at age $t$ is $e^{-\lambda t}$. For an agent at birth, the probability of dying at exact age $t$ therefore follows a Poisson distribution and is $\lambda e^{-\lambda t}$. Life expectancy is given by 


$$
Z=\int_{0}^{\infty} t\left(\lambda e^{-\lambda t}\right) d t=\frac{1}{\lambda}
$$

Similarly we assume that health status is exogenously determined, evolving as a function of life expectancy and age. Health may affect the productivity of workers and their wage rate, as well as the desire for leisure, and may create a demand for the consumption of health services. For simplicity, we assume that the only channel through which health operates is the disutility of labor.

We assume that at age $t$ the agent gets the instantaneous utility $\left[u(c(t))-\chi_{t} v(Z, t)\right]$, where $u(c(t))$ is felicity; $v(Z, t)$ is the disutility of working, assumed to be increasing in $\mathrm{t}$; and $\chi$ is an indicator function that takes the value 1 when working and 0 when retired. It is not difficult to extend the model to allow for variable labor supply (i.e., partial retirement), but in practice fixed costs associated with employment (for example, commuting time) tend to make a discrete labor supply decision fairly common.

A major feature of our model is the disutility of labor schedule, $v(Z, t)$, which rises with age $t$ and promotes retirement. In addition, we postulate that the disutility of working at age $t$ depends on life expectancy, $Z$. If this disutility is independent of $Z$, it implies that increases in life expectancy are not associated with general health improvements, and population aging creates a large cohort of older people in poor health, which is at odds with the evidence.

If health status at each age improves proportionately with life expectancy, then the disutility of labor, $v(Z, t)$, is homogeneous of degree zero in life expectancy and age as follows:

$$
v(\alpha Z, \alpha t)=v(Z, t)
$$


In other words, the health status and disutility of working of someone working at age 45 who has a life expectancy of 60 is the same as the health status and disutility of someone working at age 60 who has a life expectancy of 80 .

Lifetime expected utility is given by

$$
U=\int_{0}^{\infty} e^{-(\delta+\lambda) t}[u\{c\}-\chi v(z, t)] d t,
$$

where future utility is discounted at the subjective rate of time preference, $\delta$, and is conditional on the probability of being alive at time t. Lifetime expected utility is maximized subject to the budget constraint

$$
\frac{d W}{d t}=\chi_{t} w+(\lambda+r) W-c
$$

where $\mathrm{W}$ is the state variable, wealth. If the agent works at time $\mathrm{t}$, he or she earns the wage $w(t)$, which is added to wealth, while consumption, $c(t)$, reduces wealth. We assume that wealth can be transferred from one period to another by saving or borrowing from the financial sector. This competitive financial sector can borrow or lend freely at the interest rate $r$.

Agents, however, are paid an effective interest rate $r+\lambda$ on their savings, which is larger than $r$, to compensate them for the fact that they may die before withdrawing their savings. Similarly, agents who borrow pay the rate $r+\lambda$ to compensate the bank for the fact that they may die before repaying their borrowings. This is equivalent to treating all savings as being in the form of annuity purchases, while all borrowing has to be accompanied by an actuarially fair life insurance contract for the amount of the loan. Provided that a continuum of agents exists, the financial sector can avoid all risk by aggregating it over individuals and earns zero profits. 
The transversality condition is that $\lim W_{t} \geq 0$. Note that agents may plan to hold positive wealth indefinitely, because they do not know how long they will live. ${ }^{5}$ The control variables for the agent's optimization problem are $c$ and $\chi$. Agents must decide when to work and when to retire and what their consumption stream should be.

The Hamiltonian for this problem is

$$
H=e^{-(\lambda+\delta) t}\left[u\{c(t)\}-\chi_{t} v(z, t)\right]+\phi\left[\chi_{t} w(t)+(\lambda+r) W(t)-c(t)\right] .
$$

The following are the first-order conditions for a maximum in $c$ and $\chi:^{6}$

$$
\begin{gathered}
\dot{\phi}=-\frac{\partial H}{\partial W}=-\phi(r+\lambda), \\
\frac{\partial H}{\partial c}=e^{-(\lambda+\delta) t} u^{\prime}(c)-\phi=0, \text { and } \\
\frac{\partial H}{\partial \chi}=-e^{-(\lambda+\delta) t} v(Z, t)+\phi w(t) \geq 0 \text { when } \chi=1 \\
\frac{\partial H}{\partial \chi}=-e^{-(\lambda+\delta) t} v(Z, t)+\phi w(t) \leq 0 \text { when } \chi=0
\end{gathered}
$$

These conditions can be shown to yield the following:

$$
\begin{gathered}
\dot{c}=(r-\delta) \frac{u^{\prime}(c)}{-u^{\prime \prime}(c)} \\
\chi_{t}=1 \Leftrightarrow u^{\prime}(c) w(t) \geq v(Z, t)
\end{gathered}
$$

\footnotetext{
${ }^{5}$ The transfer of the wealth of those who die to the financial sector exactly compensates deposit-taking institutions for the fact that they pay an interest rate $r+\lambda$ on deposits that exceed the risk free rate $r$, and rules out the need to consider unintended bequests.

${ }^{6}$ Sydaeter, Storm, and Berck (1998) give sufficient conditions for a maximum. Checking that these conditions are satisfied for the explicit functional forms we employ later in the paper is straightforward.
} 
The first condition implies a rising consumption level over time if the interest rate is high, though this effect may be small if the utility function is highly concave. If the marginal utility of consumption falls quickly with the level of consumption, that is, $-u^{\prime \prime}(c)$ is large, the agent will want to smooth consumption over time. The second condition implies that agents work at time $\mathrm{t}$ so long as the utility gain from the consumption purchased by the wage they earn (the marginal utility of consumption times the wage) exceeds the disutility of working.

To investigate the agents' choices we assume the agent has constant relative risk aversion; the utility of consumption depends on the parameter $\beta$ and is given by

$$
u(c)=\frac{c^{1-\beta}}{1-\beta} \text { for } \beta \geq 0 \text { and } \beta \neq 1, \quad u(c)=\log (c) \text { for } \beta=1 .
$$

In our dynamic model, with time-separable utility, $\beta$ is both the coefficient of relative risk aversion and the inverse of the inter-temporal elasticity of substitution. We also assume the following simple explicit form for the disutility of work that obeys our homogeneity of degree zero assumption:

$$
v(Z, t)=d e^{t / Z}=d e^{\lambda t}
$$

The parameter $d$ measures the intensity of the disutility of work and potentially may vary as the nature of employment changes. Costa (1998a) suggests that poor health is becoming less important as a factor influencing labor supply decisions, which is consistent with a fall in the value of $d$ as employment evolves toward less physical work for which poor health may be less of an impediment. However, note that $d$ really measures the disutility of work relative to leisure, and the expansion in the range of leisure opportunities available in old age may be increasing the attractiveness of retirement. 
Our utility function implies that marginal utility is $u^{\prime}(c)=c^{-\beta}$ and that the optimal growth rate of consumption is

$$
\frac{\dot{c}}{c}=\frac{(r-\delta)}{\beta},
$$

so that individual consumption is given by $c(t)=c_{0} e^{\left(\frac{r-\delta}{\beta}\right) t}$. The initial level of consumption, $c_{0}$, can be calculated from a re-parameterization of the budget constraint as follows:

$$
\int_{0}^{\infty} e^{-(\lambda+r) t} c(t) d t=\int_{0}^{R} e^{-(\lambda+r) t} w(t) d t
$$

Using the result that the wage grows at the rate $\sigma$ while consumption grows at the rate $\frac{r-\delta}{\beta}$ gives us

$$
\int_{0}^{\infty} e^{-(\lambda+r) t} c_{0} e^{\left(\frac{r-\delta}{\beta}\right) t} d t=\int_{0}^{R} e^{-(\lambda+r) t} w_{0} e^{\sigma t} d t
$$

or

$$
c_{0}\left[\frac{e^{-\left(\frac{r(\beta-1)+\lambda \beta+\delta}{\beta}\right) t}}{-\left(\frac{r(\beta-1)+\lambda \beta+\delta}{\beta}\right)}\right]_{0}^{\infty}=w_{0}\left[\frac{e^{(\sigma-(\lambda+r)) t}}{\sigma-(\lambda+r)}\right]_{0}^{R},
$$

and so

$$
c_{0}=w_{0} \frac{(r(\beta-1)+\lambda \beta+\delta)}{\beta(\lambda+r-\sigma)}\left(1-e^{(\sigma-\lambda-r) R}\right) .
$$

For the model to make sense, we require that $\sigma<r+\lambda$. If this is not the case, the net present value of lifetime wage earnings can be infinite and the budget constraint shown in equation (15) is not well defined. Because we want to examine outcomes as the death rate, $\lambda$, varies, we assume that $\sigma<r$ so that the finite budget constraint holds for any death rate. 
The retirement age $R$ is given by the marginal condition that the disutility of working just equals the utility of the consumption from the wage earned:

$$
v(R)=w(R) u^{\prime}(c(R))
$$

which can be written as

$$
d e^{\lambda R}=w_{0} e^{\sigma R}\left[c_{0} e^{\frac{(r-\delta)}{\beta} R}\right]^{-\beta}
$$

Equations (17) and (19) give us two marginal conditions with two unknowns, the retirement age and the initial level of consumption (together with equation (13) this determines the time path of consumption), emphasizing that these are joint decisions. We sketch the two equations in figure 1 (for the case $\delta=r=\sigma=0$ ). In this case consumption is constant over the lifespan. The first order conditions for optimal lifetime consumption and savings generate the initial consumption level, given by equation (14), that gives a positive relationship between retirement and consumption since later retirement allows for a higher level of lifetime consumption (the consumption level converges to the constant wage level $w$ as the retirement age rises). On the other hand, the first-order condition for optimal retirement given by equation (15) gives a downward sloping relationship between the retirement age and consumption level; the agent works longer only if the marginal utility gained from the extra consumption this allows is sufficiently high, implying that the level of consumption must be lower. The intersection of the two curves gives the optimal retirement - consumption choice (shown by $R^{*}$ and $c^{*}$ ).

Substituting for the initial level of consumption in equation (19) gives us

$$
d e^{\lambda R}=w_{0}^{1-\beta}\left[\frac{\beta(\lambda+r-\sigma)}{(r(\beta-1)+\lambda \beta+\delta)}\right]^{\beta} \frac{e^{(\sigma+\delta-r) R}}{\left(1-e^{(\sigma-\lambda-r) R}\right)^{\beta}},
$$


which is an implicit function of the retirement age $R$ alone. ${ }^{7}$ Similarly, we substitute out the retirement age in equation (19) and derive an equation that is an implicit function of $c_{0}$, the initial level of consumption, alone:

$$
c_{0}=w_{0} \frac{(r(\beta-1)+\lambda \beta+\delta)}{\beta(\lambda+r-\sigma)}\left(1-\left(\frac{w_{0} c_{0}^{-\beta}}{d}\right)^{\frac{\sigma-\lambda-r}{\lambda-\delta-\sigma+r}}\right),
$$

We now have a set of equations that could provide the solution to the agent's maximization problem. Equation (20) can be solved to give the retirement age, $R$. Equation (21) can be solved to give the initial level of consumption, $c_{0}$, which together with equation (13) gives us a complete solution for the agent's labor supply and consumption decisions.

\section{Retirement and Consumption Decisions}

We now apply our theoretical model to analyze the determinants of retirement and savings behavior. In general, we cannot find explicit solutions to equations (20) and (21) for an arbitrary value of $\beta$; we therefore examine behavior for a particular values of $\beta$, the coefficient of relative risk aversion. Evidence from the asset pricing literature implies that a high value of $\beta$ is required to explain the equity premium and the volatility of asset prices. Chetty and Szeidl (2004) suggest that this requirement imposes a lower bound on $\beta$ of at least 2 . However, the low empirical estimates we have of the elasticity of labor supply with respect to wages imply a low value for $\beta$. Chetty (2003) argues that a value of $\beta$ as high as 2 can only be supported by the most extreme empirically estimated value of the elasticity of labor supply to wage changes. ${ }^{8}$ We

\footnotetext{
${ }^{7}$ If the rate of wage growth is extremely high while the disutility of labor grows slowly, this equation may have no finite solution. However, provided that $\sigma<\lambda+r-\delta$, the growth rate of the disutility of labor dominates and the agent will eventually retire.

${ }^{8}$ Chetty's work indicates that most estimates of the elasticity imply a value of $\beta$ close to unity.
} 
use a value of $\beta=2$ as our benchmark for the utility function. (We also give results for the case where $\beta=1$ [log utility] for comparison.)

While we have a potential solution, solving the implicit functions (20) and (21) for $R$ and $c_{0}$ is complex, and we cannot find a complete closed-form solution. Our approach is to use the implicit function theorem to obtain an approximation around a special case for which we do have a complete closed-form solution. This special case is where the rate of time preference, rate of interest, and growth rate of wages are all zero $(\delta=r=\sigma=0)$. For this set of parameter values we can write equation (20) as

$$
d e^{\frac{R}{Z}}=w_{0}^{1-\beta}\left[\left(1-e^{-\frac{R}{Z}}\right)\right]^{-\beta}
$$

Clearly this is an implicit function of $R / Z$ and has a solution of the form given by

$$
\frac{R}{Z}=f\left(w_{0}, d, \beta\right)
$$

In this case, the optimal retirement age is a fixed proportion of life expectancy, with the proportion depending on the parameters of the agent's utility function and on the wage rate.

As $r=\delta=0$, consumption is clearly steady over time. The level of consumption is fixed at the initial level, which is the solution to

$$
c_{0}=w_{0}\left(1-\frac{d}{w_{0} c_{0}^{-\beta}}\right) \text {. }
$$

This implies that the optimal consumption level, which solves this equation, is independent of life expectancy and can be written as 


$$
c_{0}=g\left(w_{0}, d, \beta\right)
$$

For $\beta=2$ and $\delta=r=\sigma=0$, we can solve these equations to give the complete closedform solution ${ }^{9}$ as follows:

$$
R=\log \left[\frac{1+2 d w_{0}+\sqrt{1+4 d w_{0}}}{2 d w_{0}}\right] Z, \quad c_{0}=\frac{\sqrt{1+4 d w_{0}}-1}{2 d}
$$

In terms of figure 1 , an increase in life expectancy shifts both curves to the right. In order to maintain a given level of consumption with a longer lifespan the agent must work for a longer period, moving the curve representing first order condition for optimal consumption-savings to the right. At the same time, at a given level of consumption, and marginal utility of earnings, an increase in health and lifespan reduces the disutility of work and encourages a longer working life, moving the curve representing the first order condition for optimal retirement to the right. When $\delta=r=\sigma=0$ the net effect of the shift in the two curves is to raise the retirement age proportionately with life expectancy, without changing the level of consumption.

However, we want to get some idea of how changes in the interest rate and the rate of growth of wages affect retirement and savings behavior. We also want to study how changes in health and life expectancy affect retirement and consumption when rates of time preference, interest, and wage growth are not zero.

We therefore proceed to find an approximation to the solution to equations (20) and (21) by using the implicit function theorem to linearize the solution for $R$ and $c_{0}$ around the point $\delta=r=\sigma=0$. This will give us a good approximation to the solution provided that $r, \delta$, and $\sigma$

\footnotetext{
${ }^{9}$ This is the unique solution; a second formal solution exists but it implies a negative retirement age.
} 
are small. Appendix 1 shows how we go about carrying out this approximation. ${ }^{10}$ When $\beta=2$ and $r, \delta$, and $\sigma$ are small ${ }^{11}$, we have the approximation:

$$
\begin{aligned}
& R=\log \left[\frac{1+2 d w_{0}+\sqrt{1+4 d w_{0}}}{2 d w_{0}}\right] Z \\
& +\left(\log \left(\frac{1+2 d w_{0}+\sqrt{1+4 d w_{0}}}{2 d w_{0}}\right)-\frac{2}{\sqrt{1+4 d w_{0}}}\right) Z^{2} \sigma \\
& +\left(\frac{1}{\sqrt{1+4 d w_{0}}}+\log (2)-\log \left(\frac{1+2 d w_{0}+\sqrt{1+4 d w_{0}}}{d w_{0}}\right)\right) Z^{2} r \\
& +\frac{\left(\log \left(\frac{1+2 d w_{0}+\sqrt{1+4 d w_{0}}}{2 d w_{0}}\right)-1\right)}{\sqrt{1+4 d w_{0}}} Z^{2} \delta
\end{aligned}
$$

and for initial consumption we have

$$
\begin{aligned}
& c_{0}=\frac{\sqrt{1+4 d w_{0}}-1}{2 d}+\frac{\sqrt{1+4 d w_{0}}-1}{4 d \sqrt{1+4 d w_{0}}} Z(2 \sigma-r) \\
& +\frac{\sqrt{1+4 d w_{0}}-1+\left(\sqrt{1+4 d w_{0}}-1\right)^{2} \log \left(\frac{4 d w_{0}}{\left(\sqrt{1+4 d w_{0}}-1\right)^{2}}\right)}{4 d \sqrt{1+4 d w_{0}}} Z \delta
\end{aligned}
$$

Table 1 shows the effects on the retirement age and initial consumption of changes in the parameters implied by these equations.

\footnotetext{
${ }^{10}$ The details of the calculations for each slope in the approximation equations (27) and (28) are available in the web appendix at http://www.qub-efrg.com/uploads/Web_Appendix.ZIP. This file contains Mathematica notebooks for each calculation.

${ }^{11}$ The results for $\beta=1$ (log utility) are given in appendix 2 .
} 
Table 1: Summary of Comparative Statics Results for $\beta=2$

\begin{tabular}{|c|c|c|}
\hline $\begin{array}{l}\text { Parameter } \\
\text { Increased }\end{array}$ & Retirement age & Initial consumption \\
\hline Interest rate, $r$ & Falls & Falls \\
\hline $\begin{array}{l}\text { Rate of time } \\
\text { preference, } \delta\end{array}$ & $\begin{array}{c}\text { Falls } \\
\text { if } R<Z \text { when } \\
r=\delta=\sigma=0\end{array}$ & Rises \\
\hline Wage growth rate, $\sigma$ & Rises & Rises \\
\hline Disutility of labor, $d$ & Falls & Falls \\
\hline Initial wage level, $w_{0}$ & Falls & $\begin{array}{l}\text { Rises but less than } \\
\text { proportionately }\end{array}$ \\
\hline $\begin{array}{l}\text { Health and life } \\
\text { expectancy, Z }\end{array}$ & $\begin{array}{l}\text { Rises, but less than } \\
\text { proportionately if } r=\delta \\
\text { and if } R<Z \text { when } \\
r=\delta=\sigma=0\end{array}$ & Rises if $r=\delta$ \\
\hline
\end{tabular}

The effects shown in table 1 can be derived as follows. From equations (27) and (28), an increase in the interest rate clearly leads to lower initial consumption and higher savings and, from equation (13), leads to steeper growth in consumption over time. A higher interest rate also leads to earlier retirement as demonstrated in appendix 3(i). A rise in the interest rate encourages saving, reducing consumption early on in life and increasing consumption during old age. The higher consumption during old age lowers the marginal utility of consumption, reducing the incentive to work and increasing the demand for leisure (i.e., early retirement).

An increase in the rate of time preference encourages initial consumption at the expense of a slower growth rate in consumption over time. The effect of an increase in the rate of time preference on the retirement age is ambiguous. However, if $R<Z$ when $r=\delta=\sigma=0$, then $\log \left[\frac{1+2 d w_{0}+\sqrt{1+4 d w_{0}}}{2 d w_{0}}\right]<1$ and an increase in the rate of time preference lowers the retirement age. The intuition for this result is that an increase in the rate of time preference tilts 
the profile of consumption over time, resulting in higher consumption when young and lower consumption when old. This means that as long as $R$ is not too high, the level of consumption is higher and its marginal utility is lower at retirement age. The lower marginal utility of consumption decreases the benefits of working and encourages earlier retirement.

Appendix 3(ii) shows that the sign of the slope of retirement with respect to wage growth is positive. An increase in the rate of wage growth with age encourages workers to postpone retirement to take advantage of the relatively higher wages when they are older. Clearly, higher wage growth leads to a rise in consumption throughout life. Indeed, young workers may even borrow to finance a high level of consumption based on the promise of high wages later in life.

When $r, \delta$, and $\sigma$ are small, the first term in both equation (27) and equation (28) dominates the effect of changes in the disutility of labor. Increasing the disutility of work parameter leads to earlier retirement. This early retirement requires a reduction in consumption because of the need for more savings for retirement.

For the case of changes in the level of wages, once again the first term in equation (27) and equation (28) dominates the effect. Clearly consumption rises with the level of wages, but less than proportionately, while the retirement age falls, implying that the rate of saving increases. A high level of wages encourages a longer working life through the substitution effect. At the same time it makes workers richer and the income effect leads to a greater demand for leisure. For values of $\beta>1$, the income effect dominates, leading to earlier retirement. Indeed, rising income levels can potentially account for the long, secular decline in the retirement age over the last 150 years in industrial countries.

An increase in health and life expectancy acts as an increase in endowment. When $r, \delta$, and $\sigma$ are all zero, an increase in health and life expectancy lead to a proportional increase in 
working life, leaving the level of consumption during each period unchanged. This is a general result, independent of the felicity function (as shown in Bloom, Canning, and Graham 2003). The intuition for this is that an increase in health and life expectancy can be thought of as stretching time and can be formally captured by a simple change in the time variable that leaves the optimization problem, expressed as a function of the proportion of lifespan worked, unchanged.

When $r, \delta$, and $\sigma$ are small, the first term in equation (27) dominates the effect of an increase in life expectancy on retirement, so retirement still rises with life expectancy. However, the proportion of life spent working declines, as shown in appendix 3(iii). From equation (28) it is clear that initial consumption rises in response to longer life expectancy if $r=\delta,{ }^{12}$ and equation (13) implies that consumption rises throughout the life cycle.

Table 1 shows only the effect of life expectancy on retirement and consumption. Now consider the effect on the savings rate during working life when life expectancy increases. Higher consumption at each point in time, together with a lower total return on savings due to a smaller $\lambda$ and lower annuity rates, means wealth rises more slowly when life expectancy increases. Hence consumption rises, and income (including the return on wealth) falls, reducing the observed saving rate of a worker at each age. This reduced savings rate only holds when the comparison is between two workers. Eventually the worker with the shorter life span will retire and have a low savings rate (out of a much lower income) while the worker with a longer lifespan stays in employment and keeps saving for retirement. However, conditional on being employed, a longer lifespan will generate a lower savings rate at each age.

\footnotetext{
${ }^{12}$ This is a sufficient condition. The proof can clearly be relaxed to $r<k \delta$ for some $\mathrm{k}>1$.
} 
The intuition for this result is that an increase in life expectancy magnifies the compounding effects of wage growth, interest rates, and time preference. For example, suppose that only the interest rate is positive and the agent keeps to the proportionality result that holds in the case of $r, \delta$, and $\sigma$ all being zero when life expectancy rises. Now when life expectancy rises, upon reaching retirement age the agent will have greater wealth than before because of the increased effects of interest compounding over a longer working life. The higher level of accumulated assets allows a higher level of consumption (spread over the entire lifespan) which induces a lower marginal utility of consumption, reducing the incentive to work and encouraging earlier retirement. The wealth effect generated by compound interest over a longer lifespan leads to both an increase in consumption and an increase in leisure (early retirement).

While the proportion of lifetime spent in employment falls as health and longevity rise, it is important to note that absolute length of the working lifetime must increase sufficiently to generate higher wealth at retirement than before despite a lower savings rate, in order to finance a higher level of consumption over a longer period of retirement. This indicates that the fall in the proportion of lifetime worked cannot be too great and that the main effect of increased health and longevity is to increase the length of the working life.

\section{Conclusion}

Our model demonstrates three major, long-term influences on the optimal age at retirement and on savings behavior. First, at higher levels of lifetime income, the desire for increased leisure leads to early retirement funded through a higher savings rate. Second, a lower intrinsic disutility of working, as employment moves away from manual labor, leads to longer 
working lives and less need to save for retirement, though this effect may be offset by increased opportunities for leisure activities. Third, longer life spans and healthier lives lead to an increase in working life. However, the longer life span allows the enjoyment of compound interest on savings for a longer period, and this leads to a reduction in both the proportion (though not the number of years) of the life span spent in employment and in the savings rate.

We also find effects due to the rate of time preference, the interest rate, and the rate of wage growth. These variables may change, for example, the interest rate may fall with increased levels of investment as aging populations save for retirement, and the rate of wage growth may rise if the rate of technical progress increases. Changes in these variables are, however, likely to be small.

While our model may help predict actual behavior, a more realistic approach would allow for market imperfections, institutionalized transfer arrangements, and less than fully rational behavior. However, our results do give the optimal retirement and savings behavior of fully rational agents under complete and perfect capital markets, and can therefore be thought of as a benchmark for the design of social security systems whose objective is to promote such an outcome.

\section{Appendix 1: Linear Approximation}

Let $x=\left(w_{0}, \lambda, d, \sigma, r, \delta\right)$. For $x_{0}=\left(w_{0}, \lambda, d, 0,0,0\right)$ the retirement age is the implicit solution to equation (20). Now define

$$
F(R, x)=d e^{\lambda R}-w_{0}^{1-\beta}\left[\frac{\beta(\lambda+r-\sigma)}{(r(\beta-1)+\lambda \beta+\delta)}\right]^{\beta} \frac{e^{(\sigma+\delta-r) R}}{\left(1-e^{(\sigma-\lambda-r) R}\right)^{\beta}}
$$


By the implicit function theorem we can write the optimal retirement age in the neighborhood of $\mathrm{x}_{0}$ as a unique differentiable function

$$
R^{*}(x)=R^{*}\left(w_{0}, \lambda, d, \sigma, r, \delta\right)
$$

where

$$
F\left(R^{*}(x), x\right)=0
$$

as long as the partial derivatives of $\mathrm{F}$ are continuous (which is clear) and $\frac{\partial F(R, x)}{\partial R} \neq 0$.

Furthermore the implicit function theorem implies that

$$
\frac{d R^{*}}{d x}=-\frac{\delta F / \delta x}{\delta F / \delta R^{*}}
$$

We can calculate this by differentiating F. Applying Taylor's Theorem,

$$
R^{*}(x) \approx R^{*}\left(x_{0}\right)+\left.\left(x-x_{0}\right) \frac{\delta R^{*}}{\delta x}\right|_{x=x_{0}}
$$

We can expand this around $x_{0}=\left(w_{0}, \lambda, d, 0,0,0\right)$ to give

$$
R^{*}(x) \approx R\left(x_{0}\right)+\left.\sigma \frac{\partial R^{*}}{\partial \sigma}\right|_{x=x_{0}}+\left.r \frac{\partial R^{*}}{\partial r}\right|_{x=x_{0}}+\left.\delta \frac{\partial R^{*}}{\partial \delta}\right|_{x=x_{0}}
$$

Similarly, we can use the implicit function

$$
G\left(c_{0}, x\right)=c_{0}-w_{0} \frac{(r(\beta-1)+\lambda \beta+\delta)}{\beta(\lambda+r-\sigma)}\left(1-\left(\frac{w_{0} c_{0}^{-\beta}}{d}\right)^{\frac{\sigma-\lambda-r}{\lambda+\delta-\sigma-r}}\right)
$$

to derive an approximation for the initial level of consumption. 


\section{Appendix 2: The case of $\beta=1$}

Taking $\beta=1$, which implies that felicity is logarithmic in consumption, and assuming $\delta=r=\sigma=0$, our solution takes the simple form

$$
R=\log \left(\frac{1+d}{d}\right) Z, \quad c_{0}=\frac{1}{1+d} w_{0} .
$$

In this case, the wage level, $w_{0}$, has no effect on the retirement age, $R$. In general, a higher wage increases the incentive to work longer (the substitution effect), but it also raises lifetime income and increases the demand for leisure and retirement (the income effect). With log utility these income and substitution effects exactly cancel.

Our first-order approximation to the optimal retirement age, which holds when $r, \delta$, and $\sigma$ are small, is

$$
R=\log \left(\frac{1+d}{d}\right) Z+\left[\frac{(1+d) \log \left(\frac{1+d}{d}\right)-1}{(1+d)}\right](\sigma-r) Z^{2}-\left[\frac{1-\log \left(\frac{1+d}{d}\right)}{(1+d)}\right] \delta Z^{2}
$$

Similarly, we can find an approximation for initial consumption as follows:

$$
c_{0}=\frac{w_{0}}{1+d}+\frac{1}{(1+d)^{2}}(\sigma-r) Z w_{0}+\frac{1+d \log \left(\frac{1+d}{d}\right)}{(1+d)^{2}} \delta Z w_{0}
$$

The details of the calculations for each slope in the approximation are available in the web appendix at http://www.qub-efrg.com/uploads/Web_Appendix.ZIP.

Table 2 shows effects on behavior of changes in our parameters for $\beta=1$ 
Table 2: Summary of Comparative Statics Results for $\beta=1$

\begin{tabular}{|l|c|c|}
\hline \multicolumn{1}{|c|}{$\begin{array}{c}\text { Parameter } \\
\text { Increased }\end{array}$} & Retirement age & Initial consumption \\
\hline Interest rate, $\mathrm{r}$ & Falls & Falls \\
\hline $\begin{array}{l}\text { Rate of time } \\
\text { preference, } \delta\end{array}$ & $\begin{array}{c}\text { Falls } \\
\text { if } R<Z \text { when } \\
r=\delta=\sigma=0\end{array}$ & Rises \\
\hline Wage growth rate, $\sigma$ & Rises & Falls \\
\hline Disutility of labor, $\mathrm{d}$ & Falls & Rises proportionately \\
\hline Initial wage level, $w_{0}$ & Unchanged & $\begin{array}{c}\text { Rises } \\
\text { if } r=\delta\end{array}$ \\
\hline $\begin{array}{l}\text { Health and life } \\
\text { expectancy, } \mathrm{Z}\end{array}$ & $\begin{array}{c}\text { Rises, but less than } \\
\text { proportionately } \\
\text { if } R<Z \text { when } \\
r=\delta=\sigma=0\end{array}$ & \\
\hline
\end{tabular}

The results in table 2 are very similar to those presented in table 1 . The main difference is that the initial wage level now has no effect on the retirement age, with consumption rising proportionately with the level of income (as opposed to less than proportionately for the case of $\beta=2$ ). Most of the signs in table 2 can be derived from inspection of equations (37) and (38).

Note that the condition $R<Z$ when $r=\delta=\sigma=0$ now implies that $\log \left(\frac{1+d}{d}\right)<1$.

To ascertain the effect of both the interest rate and wage growth rate on the age at retirement, note that $(1+d) \log \left(\frac{1+d}{d}\right)>1$. To prove this, consider the following. For $d=0$, the LHS is clearly infinite. Taylor's theorem implies that $\log (1+\mathrm{x})$ is approximately equal to $\mathrm{x}$ when $\mathrm{x}$ is small, so for $d$ large we have that $\log \left(1+\frac{1}{d}\right) \approx \frac{1}{d}$ and the LHS $\approx 1+\frac{1}{d}$. Taking the limit as $d \rightarrow \infty$, this approximation becomes increasingly good and the LHS $\rightarrow 1$. 
We now argue that the slope of the LHS is never positive; this rules out LHS $<1$ since that would imply a positive slope as the LHS rises to 1 as $d$ gets large. Suppose that LHS $<1$ for some finite positive $d_{0}$, then by the mean value theorem, a value $d_{l}$ (between $d_{0}$ and $\infty$ ) exists for which the derivative of the LHS is positive. This implies that for $d_{1}, \log \frac{1+d_{1}}{d_{1}}>\frac{1}{d_{1}}$.

Setting $c=\frac{1}{d_{1}}$, this implies that $\log (1+c)>c$. Now consider the function

$\log (1+x)$. For $\mathrm{x}=0$ we have $\log (1+0)=0$. Using the mean value theorem once again we can find a $\mathrm{k}$ between 0 and $c$ such that $\left.\frac{d \log (1+x)}{d x}\right|_{x=k}>1$, but this implies that $\frac{1}{1+k}>1$, for $\mathrm{k}>$ 0 , which is a contradiction.

The lack of any effect of the level of income on retirement in this case makes it difficult to explain the long downward trend in the retirement age we have observed over the last 150 years and suggests that a value of $\beta$ greater than one may be more realistic.

\section{Appendix 3: Signing the Elements of Table 1}

(i) Sensitivity of Retirement to a Change in the Interest Rate

We need to show that $\left(\frac{1}{\sqrt{1+4 d w_{0}}}+\log (2)-\log \left(\frac{1+2 d w_{0}+\sqrt{1+4 d w_{0}}}{d w_{0}}\right)\right)<0$. As $d w_{0} \rightarrow 0^{+}$, the LHS approaches $-\infty$. As $d w_{0} \rightarrow \infty$, the LHS $\rightarrow 0$. Suppose that for some $d w_{0}$ the LHS is strictly positive. Then by the mean value theorem, exists a value for $d w_{0}$ exists for which the derivative of the LHS is negative. However, differentiating the LHS with respect to $d w_{0}$ gives us $\frac{1+2 d w_{0}}{d w_{0}\left(1+4 d w_{0}\right)^{3 / 2}}($ see Mathematica file Sign R2r in the web appendix), which is clearly positive 
for all positive values of $d w_{0}$. This is a contradiction that implies that the LHS is always negative.

(ii) Sensitivity of Retirement to a Change in the Rate of Wage Growth

We need to show that $\left(-\frac{2}{\sqrt{1+4 d w_{0}}}+\log \left(\frac{1+2 d w_{0}+\sqrt{1+4 d w_{0}}}{2 d w_{0}}\right)\right)>0$. As $d w_{0} \rightarrow 0^{+}$, the LHS approaches $+\infty$. As $d w_{0} \rightarrow \infty$, the LHS $\rightarrow 0$. Suppose that for some $d w_{0}$ the LHS is strictly negative. Then by the mean value theorem, a value exists for $d w_{0}$ for which the derivative of the LHS is positive. However, differentiating the LHS with respect to $d w_{0}$ gives us $-\frac{1}{d w_{0}\left(1+4 d w_{0}\right)^{3 / 2}}$ (see Mathematica file Sign R2sig in the web appendix), which is clearly negative for all positive values of $d w_{0}$. This is a contradiction that implies that the LHS is always positive.

(iii) Sensitivity of Retirement to a Change in Life Expectancy

Consider the expression $\sigma<r=\delta$ for the retirement age $R$. The effect of life expectancy on $R$ when $r, \delta$, and $\sigma$ are small is dominated by the first term of equation (21). The coefficient on $Z$ in this term is positive, which implies that retirement age increases with life expectancy. To find the effect of increases in life expectancy on $\frac{R}{Z}$, we simply divide through the expression for $R$ by $Z$. The effect of $Z$ on this ratio is now given by 


$$
\begin{aligned}
& \frac{\partial \frac{R}{Z}}{\partial Z}=\left(\log \left(\frac{1+2 d w_{0}+\sqrt{1+4 d w_{0}}}{2 d w_{0}}\right)-\frac{2}{\sqrt{1+4 d w_{0}}}\right) \sigma \\
& +\left(\frac{1}{\sqrt{1+4 d w_{0}}}+\log (2)-\log \left(\frac{1+2 d w_{0}+\sqrt{1+4 d w_{0}}}{d w_{0}}\right)\right) r \\
& +\frac{\left(\log \left(\frac{1+2 d w_{0}+\sqrt{1+4 d w_{0}}}{2 d w_{0}}\right)-1\right)}{\sqrt{1+4 d w_{0}}} \delta
\end{aligned}
$$

From our foregoing proofs, the coefficients on $r$ and $\delta$ are both negative, as long as $R<Z$ when $r=\delta=\sigma=0$; however, the coefficient on $\sigma$ is positive. A sufficient condition for $\partial \frac{R}{Z}$

$\frac{Z}{\partial Z}<0$ is $\sigma \leq r=\delta$ (in addition to $R<Z$ when $r=\delta=\sigma=0$ ). In this case, the derivative is bounded above by

$$
\left(\begin{array}{l}
\log \left(\frac{1+2 d w_{0}+\sqrt{1+4 d w_{0}}}{2 d w_{0}}\right)-\frac{2}{\sqrt{1+4 d w_{0}}} \\
+\frac{1}{\sqrt{1+4 d w_{0}}}+\log (2)-\log \left(\frac{1+2 d w_{0}+\sqrt{1+4 d w_{0}}}{d w_{0}}\right) \\
+\frac{\log \left(\frac{1+2 d w_{0}+\sqrt{1+4 d w_{0}}}{2 d w_{0}}\right)-1}{\sqrt{1+4 d w_{0}}}
\end{array}\right) r
$$

which equals 


$$
\left(\frac{\log \left(\frac{1+2 d w_{0}+\sqrt{1+4 d w_{0}}}{2 d w_{0}}\right)-2}{\sqrt{1+4 d w_{0}}}\right) r
$$

This is clearly negative under our assumption that the retirement age is less than life expectancy in the benchmark case. 


\section{References}

Bloom, D. E., D. Canning, and B. Graham. 2003. "Longevity and Life-Cycle Savings." Scandinavian Journal of Economics 105: 319-38.

Bound, J. 1991. "Self-Reported Versus Objective Measures of Health in Retirement Models." Journal of Human Resources 26: 106-38.

Chang, F-R. 1991. "Uncertain Lifetimes, Retirement, and Economic Welfare." Economica 58: $215-32$.

Chetty, R. 2003. “A New Method of Estimating Risk Aversion.” Working Paper no. 9988. National Bureau of Economic Research, Cambridge, MA.

Chetty, R., and A. Szeidl. 2004. "Consumption Commitments and Asset Prices." Working Paper. University of California, Economics Department, Berkeley.

Costa, D. L. 1998a. The Evolution of Retirement: An American Economic History, 1880-1990. National Bureau of Economic Research Series on Long-Term Factors in Economic Development. Chicago: University of Chicago Press. . 1998b. "The Evolution of Retirement: Summary of a Research Project." American Economic Review 88: 232-36.

Cutler D.M., Poterba J.M., Sheiner L.M. and Summers L.H. 1990, "An Aging Society: Opportunity or Challenge?", Brookings Papers on Economic Activity 1: 1-56.

Deaton A. and Paxson C. (2000), "Growth, Demographic Structure, and National Saving in Taiwan," Population and Development Review 26, Supplement: 141-173.

Ehrlich, I., and H. Chuma. 1990. "A Model of the Demand for Longevity and the Value of Life Extension." Journal of Political Economy 98: 761-82. 
Feldstein, M. S. 1985. "The Optimal Level of Social Security Benefits." Quarterly Journal of Economics 10: 303-20.

Fogel, R. W. 1994. "Economic Growth, Population Theory, and Physiology: The Bearing of Long-Term Processes on the Making of Economic Policy." American Economic Review 84: 369-95. 1997. "New Findings on Secular Trends in Nutrition and Mortality: Some Implications for Population Theory." In M. Rosenzweig and O. Stark, eds., Handbook of Population and Family Economics, vol. 1A. Amsterdam: Elsevier.

Friedberg, L., and A. Webb. 2003. "Retirement and the Evolution of Pension Structure." Working Paper no. 9999. National Bureau of Economic Research, Cambridge, MA.

Gruber, J., and D. Wise.1998. "Social Security and Retirement: An International Comparison." American Economic Review 88: 158-63.

Hamermesh, D. S. 1985. "Expectations, Life Expectancy, and Economic Behavior." Quarterly Journal of Economics 10: 389-408.

Hubbard, R. G., and K. L. Judd. 1987. "Social Security and Individual Welfare: Precautionary Saving, Borrowing Constraints, and the Payroll Tax." American Economic Review 77: 630-46.

Kalemli-Ozcan, S., and D. N. Weil. 2002. "Mortality Change, the Uncertainty Effect, and Retirement." Working Paper no. 8742. National Bureau of Economic Research, Cambridge, MA.

Kalemli-Ozcan, S., H. Ryder, and D. N. Weil. 2000. "Mortality Decline, Human Capital Investment, and Economic Growth." Journal of Development Economics 62: 1-23. 
Kotlikoff, L.J. 1989. "Some Economic Implications of Life Span Extension" in Kotlikoff, L.J. What Determines Savings? Cambridge, MIT Press.

Kotlikoff, L.J., A. Spivak, and L.H. Summers. 1982. "The Adequacy of Savings", American Economic Review, 72: 1056-1069.

Laibson, D. 1998. "Life-Cycle Consumption and Hyperbolic Discount Functions." European Economic Review, 42: 861-71.

Laibson, D. I., A. Repetto, J. Tobacman, R. E. Hall, W. G. Gale, and G. A. Akerlof. 1998. "SelfControl and Saving for Retirement." Brookings Papers on Economic Activity 1998: 91196.

Lee, R. 2003. "The Demographic Transition: Three Centuries of Fundamental Change." Journal of Economic Perspectives 17: 167-90.

Lee, R. D., A. Mason, and T. Miller. 2000. "Life-Cycle Saving and the Demographic Transition: The Case of Taiwan." Population and Development Review 26, Supplement: 194-219.

Mathers, C. D., R. Sadana, J. A. Salomon, C. J. L. Murray, and A. D. Lopez. 2001. "Healthy Life Expectancy in 191 Countries, 1999." Lancet 357(9269):1685-91.

Miles D. 1999. "Modelling the Impact of Demographic Change Upon the Economy" The Economic Journal, 109: 1-37.

Nordhaus, W. 2003. "The Health of Nations: The Contribution of Improved Health to Living Standards.” In Kevin H. Murphy and Robert H. Topel, eds.), Measuring the Gains from Medical Research: An Economic Approach. Chicago: University of Chicago Press. 
Poterba, J.M. 2004. "Impact of Population Aging on Financial Markets in Developed Countries." forthcoming in Global Demographic Change: Economic Impacts and Policy Challenges, The Federal Reserve Bank of Kansas City.

Samuelson, P.A. 1958, "An exact consumption loan model of interest with or without the social contrivance of Money", Journal of Political Economy, 66: 467-482.

Sickles, R. C., and P. Taubman. 1986. "An Analysis of the Health and Retirement Status of the Elderly." Econometrica 54: 1339-56.

Skinner, J. 1985. "The Effect of Increased Longevity on Capital Accumulation." American Economic Review 75: 1143-50.

Sydaeter, K., A. Storm, and P. Berck. 1998. Economists' Mathematical Manual, 3rd ed. Berlin: Springer.

Tsai I-J, C.Y.C. Chu and C-F Chung. 2000. "Demographic Transition and Household Saving in Taiwan," Population and Development Review 26, supplement: 174-193. 
Figure 1

\section{Retirement and Consumption}

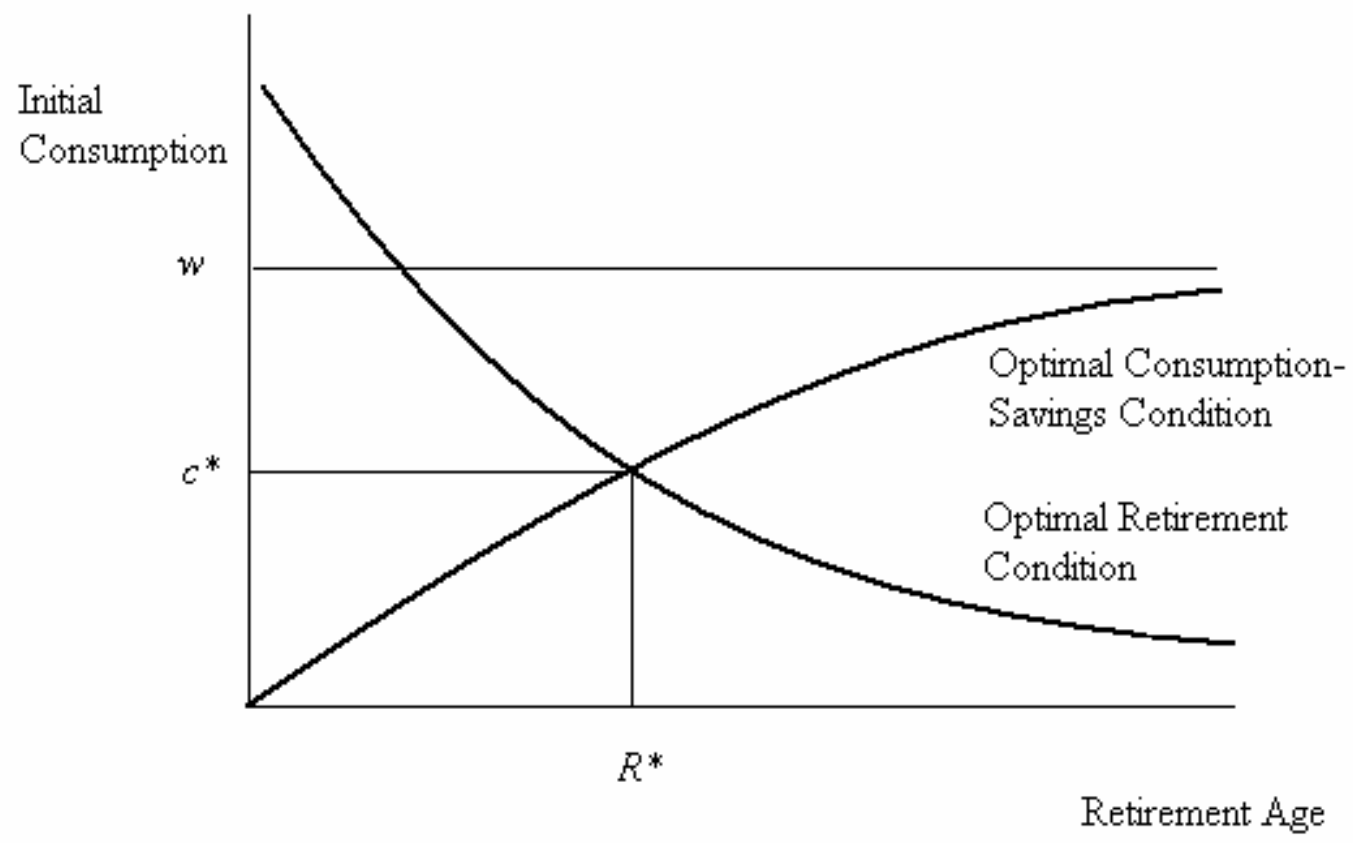

